\title{
Systemic Outlook in Technology- Management Trends of Best Technology/ICT Companies
}

\author{
Marek Jemala
}

School of Engineering and Management, University of Nova Gorica, Vipavska 13, Rožna Dolina, Nova Gorica, Slovenia, SI-5000, marek.jemala@ung.si

\begin{abstract}
In the last time, new technology generations in many industries are presented every 2-3 years. The next technology revolution is expected to be different from the previous ones because technology is present in every aspect of our society. Technology processes have more and more an interdisciplinary character, therefore must be carried out systematically and if possible in a planned form. From integration of technology processes; to customer insights that drive product and brand extensions; to spotting emerging voids that competitors miss; technology-management trends are of tremendous importance for optimum business growth and profit. The main goal of this paper is to examine particular trends related to technology-management, as well as selected business indicators of the most successful technology/ICT companies in the world. The research methodology was based on the extensive study of innovative activities described in the annual and related reports of the most profitable technology businesses.
\end{abstract}

Keywords: Technology management, technology trends, technology development, technology synergies

\section{Managerial relevance statement}

Currently, managers are forced to act on the changes that expected technology-management trends will bring. Their role is to make sense of what matters most and when to take the right actions. The emerging trends described in this paper have become the top issues that technology managers must solve with their executive colleagues. This discussion must be based on the competitive principles - in terms of what impacts the new technology-management trends will have on business effectiveness, revenue growth, profit margins, cost structure, life-cycles, etc. How these trends will affect the organization as a whole? The implementation process requires answers to questions such as: What should TM do if technology is to be leveraged for maximum value? How these trends can facilitate technological processes and improve the quality of production and business efficiency? As the new data is applied for competitive advantage, how do companies start blending ICT and technological teams? And, who will be responsible for the implementation of these new trends? These lines of thinking can raise also some of the questions about TM skills and ICT structures that need attention.

\section{Introduction}

The history of technology is the history of more and more sophisticated technology knowledge, tools and devices, and appearance of the technology-based society in recent years. If we look at history, the evolution of Technology management (TM) can be found in the $20^{\text {th }}$ century related to the improved social standard of people. In 1911, Schumpeter proposed that technological changes could induce emergence, evolution, fusion, and disruption of industries over time. The systematic roots of TM can be traced to the post-war industrial boom especially in the U.S. But, in that time, the U.S. was in high technology competition with the Soviet Union. In Europe, the success of the Marshal plan (European Recovery Program, 1948-1952) speeded up technology development processes. Within this Plan, the Economic Cooperation Administration initiated the Technical Assistance Program that funded groups of European engineers and industrialists that visited the U.S.

Received: $13^{\text {th }}$ February 2013; revised: $8^{\text {th }}$ May 2013; accepted $28^{\text {th }}$ May 2013 
and toured mines, factories, and smelters and then copied the American advances at home. At the same time, several hundred American technical advisors were sent to Europe, for the same reason. (Schain and Judt, 2001) In 1950s, the Nobel Prize holder - Robert Solow was the first to develop an economic growth model that was based the new capital produced through new technology (Solow, 1957).

Before the 1960s, the main goal behind the internationalisation of technology R\&D was to enter to a new market. In the 1970s, telecommunications and computer industries became leaders in managing international $\mathrm{R} \& \mathrm{D}$ and technology. Later, pharmaceutical, chemical and new material industries became even more science-based. (Reddy, 1997) Until the 1970s, many innovation solutions had been mostly technologydriven. The term 'strategic' was added to TM in the 1980s as a tool to offer better potential solutions for managing ambiguity, complexity and business dynamics that were caused by technology development. Along with the technology progress, increasing $\mathrm{R} \& \mathrm{D}$ and manufacturing cost were among the top issues of TM (Bohr, 1996). In the 1980s, bigger corporations started to conduct a part of their strategic R\&D activities in developing countries in order to exploit cost advantages and local markets (Reddy, 1997). Since that time, TM has become a part of international managerial strategies and processes in many institutions (companies, research and financial organizations, governmental institutions, etc.) (Pelc, 2002). Strategic $T M$ has become a process that connects strategic objectives of a company with its technology infrastructure and socioenvironmental conditions (Sahlman and Haapasalo, 2009). While, detailed technology identification and implementation are the task of operative TM. Thus, managers have been forced to mix traditional strategic thinking and demands of the developing high technology society. (Sahlman, 2010) Decisions on technology have been based on guidelines in business strategies. Technology strategies must have been in conformity with plans of strategic business units and functional departments so as to determine technology objectives that would be realizable in every part of this organization. This strategy could have following elements: technology goals and tasks, R\&D and technology portfolio, technology acquisition plan, technology budget, etc. Thus, technology planning has become a part of business and product planning and budgeting (Sahlman Haapasalo, 2009). Later, seeing the change towards a service and knowledge oriented economy, technology innovation has required more radical innovation also in the TM theory.

In the 1980s, the processes of more radical innovation stimulation caused the increasing importance of the TM development (Leifer et al., 2000) that meant more significant business opportunities in the long time, but required also more systematic managerial efforts. These efforts enable many companies to improve their organizational effectiveness (Farrukh et al., 2004). Radical technology innovations have brought the changes to industrial and market structures and allowed companies to developed so-called 'global products'. For example, the invention of high-tech - neural computing as the dawn of a new era in IT in the 1980s (Guice, 1999). IT have enormously influenced a management practice, including an integrated accounting system, design, logistics, marketing, control or sale (Roberts, 1996). Another important determinant in the TM history has become so-called trade-offs between achievement of quick profits, through the technology imitation or transfer, and on the other side - requiring higher investment in technology R\&D in a long period. Afterwards, efficient technology investment has become the basis for the success of many companies and projects. Increasingly, there have been more successful many technology specialized companies (IBM, Microsoft, Dell, Apple, later Intel, Cisco, Corning, Google, etc.) that have integrated their R\&D with emerging needs of customers, more and more using venture capital, and applying new cooperative business models (JVs, holdings, alliances, clusters, etc.). In the 1980s, TM received broad attention from both managers and academics (Drejer, 1997).

Since the 1990s, approximately 25 of the most innovative companies in the world have had in about $3 \%$ higher the average profit margin than the first 1200 companies ranked by Standard \& Poor's (Larson, 2007). For these reasons, many companies have started to create a new business, i.e. sale/lease of technology. At the same time, there was a boom of start-up science invention and intellectual ventures, i.e. companies that were primarily focused on R\&D of new technologies. The trend was in technology simplification and integration, use of artificial intelligence in TM, while technology solutions have become more complex (Rubenstein, 1994). In the 1990s, TM techniques were already resources limited and based more on retrospective understanding of the problems, rather than integrated into planned design procedures. Later, governmental pressures towards collaborative $R \& D$, leaner organisation of $R \& D$, product-process integration, etc. - dominated in TM. (Hodgson and Cardew-Hall, 1998) More and more technology services were provided by companies together with more sophisticated technology innovation. At the same time, networking have become the driving process in technology industries, and replacement of technology as hardware (HW) by software (SW) and services delivered via the Internet, socalled technology dematerialisation. Technology modularity has been a necessary precondition for technology innovation, otherwise it would soon become outdated (Poole and Simon, 1997). In that time, technology development was mainly pushed by project needs, but it appeared to be a more reactive approach not proactive in many cases (Farrukh et al., 2004). Systematic proactive technology planning and audit, networking of divisional technology, advanced expert systems, etc., these were the trends in TM in the 1990s (Rubenstein, 1994).

In 2012, China overtook the US as the world's biggest market for ICT. Germany and France have become the biggest ICT markets in Europe (Kaplinski, 2009). The expansion of intelligent ICT in many areas has caused higher requirements also for TM. TM more and more supports and integrates different processes in a company, from research, product/technology development, production and technology maintenance, to marketing. All this processes should be linked to other business processes and a strategy. Classification, modeling and simulation of technological processes increasingly reduce innovation time, but also production and operating cost (Larson, 2007). So-called traditional in-door TM is being completed by cooperative TM within open-innovation networks, or Living Labs. Integrated TM within a variety of participants and capacities 
and taking advantage of the higher openness of technology strategies have become the important factors of business success. TM methodologies tend to be more expert-based, while TM applications are more and more problem-oriented (Liao, 2005). Over the time, there have been evolved 5 main methodologies of IS that help to implement TM process: decision support systems, object oriented method, computer aided system engineering, knowledge-based systems, and database applications (Kim et al., 2003). Today, TM processes require effective identification, selection, acquisition, research, development, implementation, use and protection of technologies (elements, processes and infrastructure) necessary to achieve and sustain market positions and business performance in conformity with business objectives. ICT help TM simplify communication, planning, coordination, design, consultations, data exchange, organizational learning and memory (Archint and Batanov, 2003). Focus of TM is especially given to the front-end of innovation (Brem and Voigt, 2009). TM education has more 25 years. And, almost all main universities provide educational programs in TM, technology strategy/planning/foresight, technology-based entrepreneurship, technology innovation, technology transfer, etc. (Yanez et al., 2010). However, TM is still ill-defined in terms of the accepted methodology, tools, frameworks, with little insight in practical implementation (Farrukh et al., 2004). Table 1 indicates the development of the trends in Technology-management.

This article aims to specify the main trends in the TM, a secondary goal is to indicate possibilities of TM and business management to cope with and use these trends to improve own processes and business results. The research was based on a comprehensive study of the available scientific literature, the annual reports and related reports of the top ten technology/ ICT companies.

\section{Trends in Technology-Management in the $21^{\text {st }}$ Century}

The best technology companies achieve their outstanding results by creating specific TM teams to systematically analyze new market opportunities and trends, technological infrastructures, and to innovate their integrated (written) technology strategies and programs, for better optimization of a technology and related processes (Kepczyk, 2004). Among the most developed technological/ICT companies belong: Apple, Microsoft, IBM, Intel, Google, Oracle, etc. In the Rank of the most profitable technology companies in 2012, the most significant growth recorded Google, while this company was not included in the assessment in 2008. In the last time, the company has faced over 120 Google+ integrations to date including Google Search, YouTube and Android (Google 2011). Although, the first place in this rank belongs to Apple that has overcome the long-term world technology leaders: Microsoft, IBM or Intel. Apple continues to systematically innovate its technologies to upgrade existing products and to increase the portfolio of its product offerings through targeted $\mathrm{R} \& \mathrm{D}$, licensing of its intellectual property (IP) and acquisitions of third-party businesses and technology (Apple, 2011).

Table 1: Development of selected trends in Technology-management

\begin{tabular}{|c|c|c|c|}
\hline 1985 & 1995 & 2005 & Present \\
\hline $\begin{array}{l}\text { Technical entrepreneurship } \\
\text { inside companies }\end{array}$ & $\begin{array}{l}\text { Technology simplification, } \\
\text { miniaturisation and integration }\end{array}$ & Enterprise mobility & $\begin{array}{l}\text { Well integrated and commu- } \\
\text { nicated technology strategy }\end{array}$ \\
\hline $\begin{array}{l}\text { Debilitating central role of } \\
\text { corporate research laboratories }\end{array}$ & Leaner organisation of $R \& D$ & Fluid collaboration & Technology cooperation \\
\hline $\begin{array}{l}\text { Networking of divisional tech- } \\
\text { nology }\end{array}$ & \begin{tabular}{|l} 
Governmental pressures \\
towards collaborative $R \& D$
\end{tabular} & Web 2.0 & Open technology strategy \\
\hline $\begin{array}{l}\text { Increasing role of long-term } \\
\text { technology planning }\end{array}$ & \multirow{2}{*}{ Product-process integration } & Virtualized infrastructure & $\begin{array}{l}\text { Complex ICT solutions and } \\
» \text { clouds } \ll\end{array}$ \\
\hline $\begin{array}{l}\text { Concurrent } R \& D \text { and produc- } \\
\text { tion interface }\end{array}$ & & $\begin{array}{l}\text { Standards based interoper- } \\
\text { ability }\end{array}$ & $\begin{array}{l}\text { Platform-as-a-service archi- } \\
\text { tecture }\end{array}$ \\
\hline Technology audit & \multirow[t]{2}{*}{ Technology services } & \multirow[t]{2}{*}{ Process-centric IT } & $\begin{array}{l}\text { Converging data architec- } \\
\text { tures }\end{array}$ \\
\hline Boom of expert systems & & & Industrialized data services \\
\hline Make or Buy strategy & \multirow[b]{2}{*}{ Technology dematerialisation } & \multirow{2}{*}{$\begin{array}{l}\text { Adaptive enterprise intel- } \\
\text { ligence }\end{array}$} & Context-based services \\
\hline $\begin{array}{l}\text { Technology policy and embed- } \\
\text { ded technology capacities }\end{array}$ & & & Social-driven technologies \\
\hline Software development process & \multirow[b]{2}{*}{ Technology modularity } & \multirow{2}{*}{$\begin{array}{l}\text { Industrialised system devel- } \\
\text { opment }\end{array}$} & \multirow{2}{*}{$\begin{array}{l}\text { Orchestrated Analytical } \\
\text { Security }\end{array}$} \\
\hline $\begin{array}{l}\text { Higher effects of SBU on } \\
\text { technology }\end{array}$ & & & \\
\hline
\end{tabular}

Source: (Accenture, 2010-2012a; Bohr, 1996; Guice, 1999; Hodgson and Cardew-Hall, 1998; Poole and Simon, 1997; Reddy, 1997; Roberts, 1996; Rubenstein, 1994) 
Although, we can identify a certain decrease in above-average results in Apple in the last time.

In the Global 500 rank, among the technology companies dominates HP, followed by IBM. In this rank of the best global corporations, HP and Apple reported substantial growth compared to 2008. As part of the HP business strategy, HP commonly acquires complementary companies to divest non-core technologies or assets, enters into strategic alliances and joint ventures and makes investments to further business rise. HP has recently acquired for example: 3Com (€125mn), Palm (€124mn) and 3Par (€33mn), all from the USA (HP, 2011). More significant drops in this rank experienced Oracle and Cisco, despite the fact that Oracle is the world's largest enterprise software company and the leading provider of computer hardware products and services. Cisco is the dominant supplier of computer networking HW. Both companies have lately implemented aggressive acquisition programs to acquire supporting technology firms and thus to improve their market positions. Cisco acquired Tandberg, Norway (€8mn) and Starent Networks, USA (€36mn) (Oracle, 2011; Cisco, 2011). Qualcomm, the American global telecommunications equipment corporation (21 000 employees) is not in the Global 500 rank even though it ranked second in the Fortune Networks and other communication equipment rank, just behind the first Cisco (71 800 employees) (Fortune, 2012). (See Table 2 and Figure 1).

\subsection{Financial indicators of the most successful technology/ICT companies}

If we look at the financial results of the most successful technology/ICT companies according to revenues, then the highest revenues had HP, Apple and IBM, while, Qualcomm and Oracle had the smallest revenues in 2011, among the listed companies. Apple and HP increased their revenues in 4.5 and 3.6 times compared to 2008. But, Cisco decreased its revenues by $60 \%$ in that period. The higher differences were also in revenues per employee, while at HP and IBM it was $\$ 363429$ and $\$ 246676$ per employee, at Apple it was $\$ 1791391$ per employee in 2011. This is 4.9 to 7.3 times higher labor productivity in favor of Apple. Hence, the sales and marketing programs of Apple are interesting to mention. Apple sells its products and resells third-party products in its key markets directly to customers, but also businesses

Tab. 2: Most successful technology/ICT companies worldwide

\begin{tabular}{|c|c|c|c|c|c|c|c|c|c|c|c|}
\hline $\begin{array}{l}10 \text { most profitable tech } \\
\text { companies } 2012(2008)\end{array}$ & 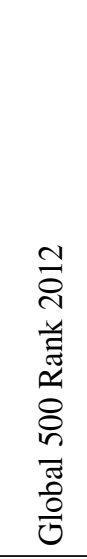 & 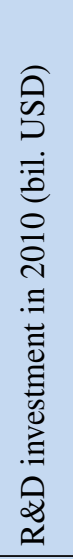 & 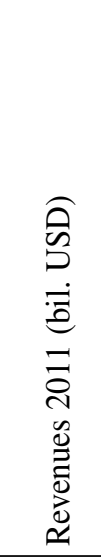 & 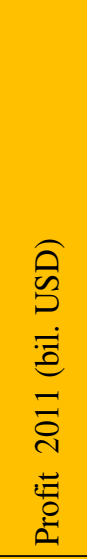 & 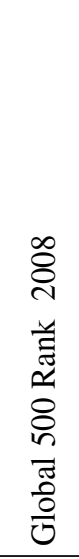 & 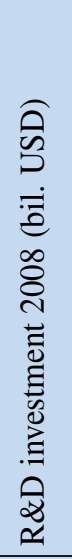 & 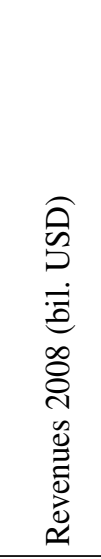 & 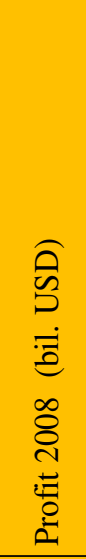 & 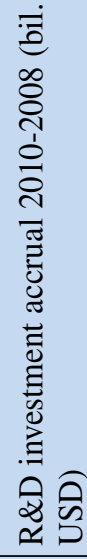 & 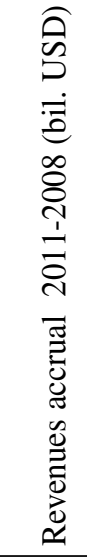 & 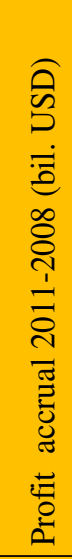 \\
\hline 1. Apple (8.) & 111. & 1,8 & 108,2 & 25,9 & 337. & 1,1 & 24,1 & 3,5 & 0,7 & 84,1 & 22,4 \\
\hline 2. Microsoft (1.) & 120. & 6,7 & 69,9 & 23,2 & 136. & 9 & 60,4 & 14,1 & $-2,3$ & 9,5 & 9,1 \\
\hline 3. IBM (2.) & 52. & 3,8 & 106,9 & 15,9 & 46. & 6 & 98,8 & 10,4 & $-2,2$ & 8,1 & 5,5 \\
\hline 4. Intel (5.) & 195. & 6,6 & 54 & 12,9 & 462. & 2,8 & 18 & 4,3 & 3,8 & 36 & 8,6 \\
\hline 5. Google & 325. & 3,8 & 37,9 & 9,7 & - & 0,7 & 5,9 & 2,2 & 3,1 & 32 & 7,5 \\
\hline 6. Oracle (6.) & 364. & 3,3 & 35,6 & 8,5 & 188. & 5,7 & 38,3 & 7 & $-2,4$ & $-2,7$ & 1,5 \\
\hline 7. HP (4.) & 28. & 2,2 & 127,2 & 7,1 & 218. & 5,2 & 34,9 & 7,3 & -3 & 92,3 & $-0,2$ \\
\hline 8. Cisco Systems (3.) & 215. & 3,9 & 43,2 & 6,5 & 41. & 3,5 & 104,3 & 7,3 & 0,4 & $-61,1$ & $-0,8$ \\
\hline 9. Qualcomm (9.) & - & 2,5 & 15 & 4,3 & - & 2,2 & 8,9 & 3,3 & 0,3 & 6,1 & 1 \\
\hline 10. Dell (10.) & 124. & 0,6 & 62,1 & 3,5 & 106. & 0,7 & 61,1 & 2,9 & $-0,1$ & 1 & 0,6 \\
\hline
\end{tabular}

Source: (Fortune, 2009a and 2012; JRC, 2009 and 2011) 


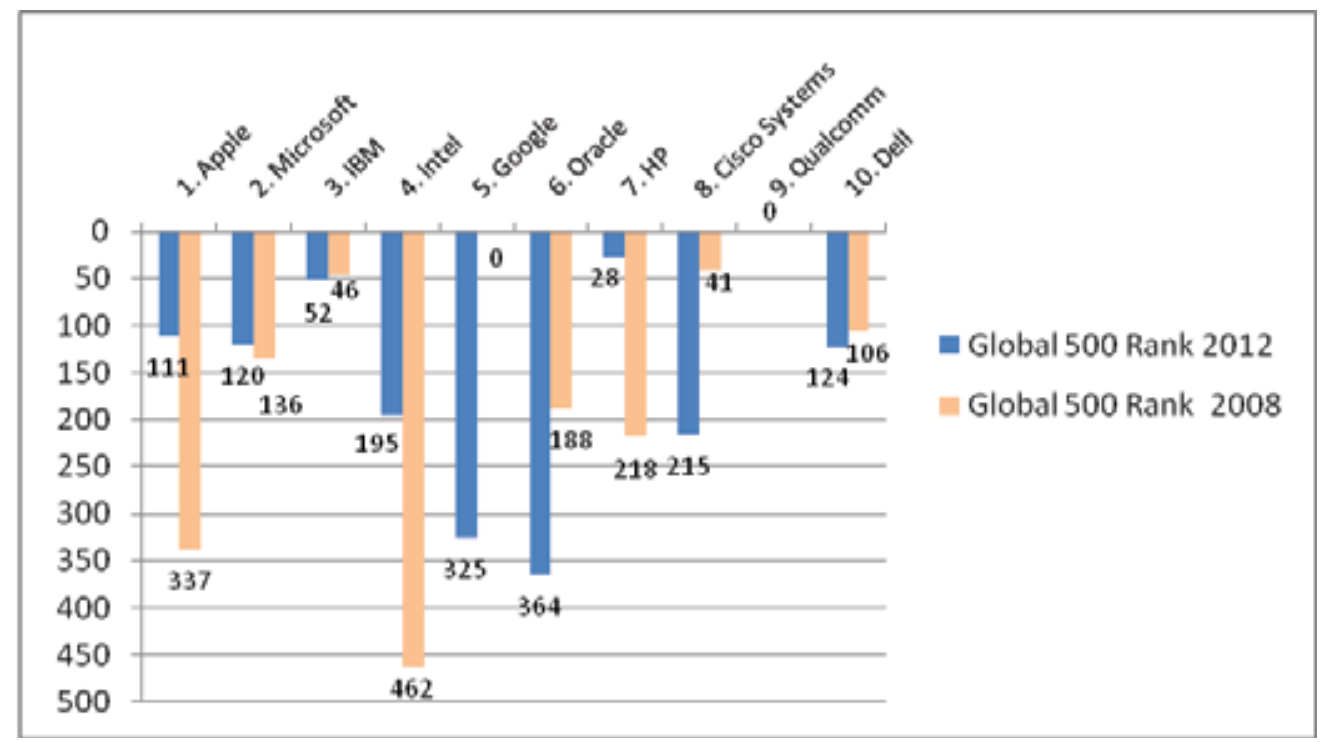

Figure 1: Most successful technology/ICT companies according to Fortune Global 500 Rank, Source: (Fortune, 2009b and 2012; JRC, 2009 and 2011)

through its unique retail and online stores. Through the Apple Premium Reseller Program, third-party resellers sell the Apple platforms by providing specific product expertise, integration and support services (Apple, 2011). HP is the top global provider of electronic products, technologies, software solutions and services to individual consumers, SMEs and large institutions, including governments, health and education organization, etc. The HP's customers are organized by the consumer and commercial customer groups: retailers, distribution partners, independent distributors, original equipment manufacturers, systems integrators, etc. The HP Enterprise Sales and Marketing organization covers most of the business and public sector customer relationships and has the primary responsibility for simplifying sales processes. (HP, 2011) IBM operates in more than 170 countries. IBM has the first position in the mainframe computers business. As it is known, IBM has radically changed its business portfolio, reducing the hardware products, while increasing its presence in higher-value markets such as services, SW and integrated solutions. As part of this business change, the company has acquired over 120 companies since 2000 (IBM, 2012b). The Cisco's products and services portfolio consists of individual and integrated offerings to connect personal and business computing devices to networks. The company provides products and services that allow customers to switch their various networks to a single multi-service data, voice, and video network, thereby enabling

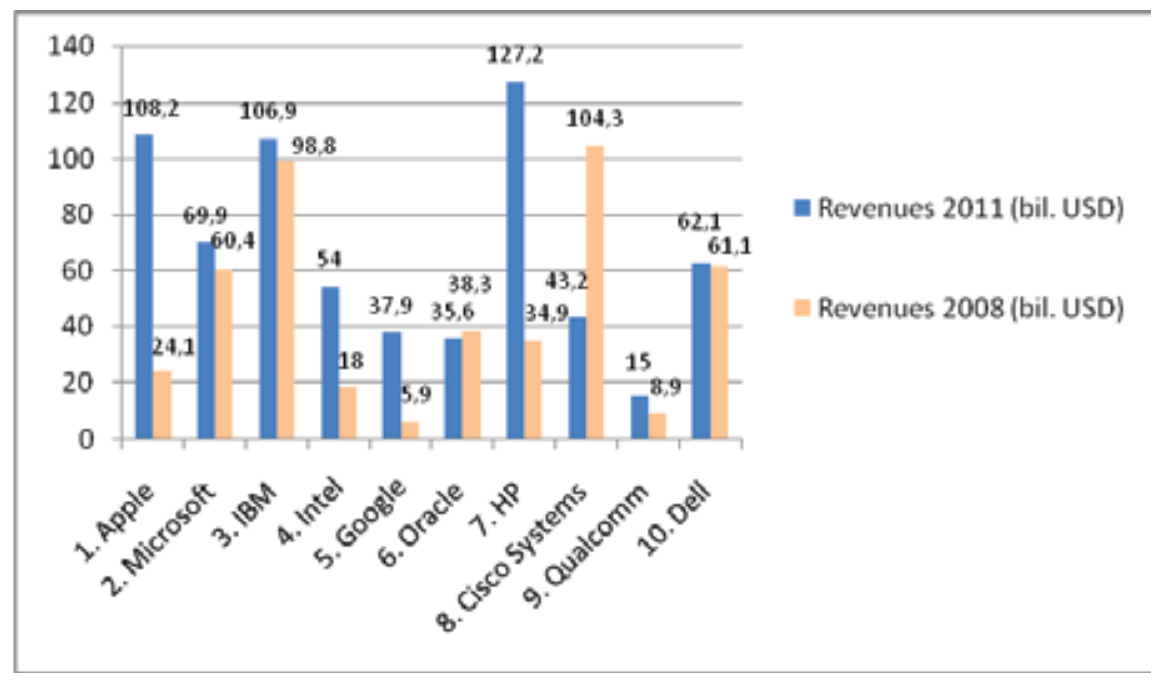

Figure 2: Most successful technology/ICT companies according to revenues, Source: (Fortune, 2009b and 2012; JRC, 2009 and 2011) 
economies of scale. The Cisco's revenues problems have been caused by four main factors: a momentum shift to the high growth internet and networking markets; the transition from an emerging to mature company; growing competition from Alcatel-Lucent, HP and other companies, and an inability to keep up with competition in recent years (Cisco, 2011). The U.S. chip maker - Qualcomm develops and supplies integrated circuits and system SW for use in voice and data communications, networking, application processing, multimedia functions and global positioning system products. The revenues from Samsung Electronics and HTC created more than $20 \%$ of the Qualcomm's revenues in fiscal 2011 (Qualcomm, 2011). (See Figure 2).

Figure 3 illustrates the best technological enterprises in terms of their profits, which are Apple, Microsoft and IBM. The lowest profits reported in this rank Qualcomm and Dell. As it is known, stock markets have experienced extreme price and volume fluctuations during the Global economic crisis that have affected the stock price of many technology companies. The Apple stock price has reflected higher growth and profitability expectations. In 2011, Apple increased its profit 7.4 times, Microsoft "only" 1.6 times, and IBM 1.5 times compared to 2008. The companies with the lowest profits in this rank: Qualcomm and Dell, increased their profits 1.3 and 1.2 times compared to 2008. The more significant differences are again in the profits per employee, while at Dell and IBM it was $\$ 33881$ and $\$ 36690$ per employee, at Apple - it was $\$ 428808$ per employee in 2011. What is 11.7 to 12.7 times higher profit per employee in favor of Apple. Microsoft and Qualcomm achieved profits approximately \$257 778 and $\$ 202830$ per employee in 2011. The Microsoft profit rise has been expected after unveiling its tablet (Surface, with the new Windows 8 OS) that should better enable to compete with Apple, Samsung or HP. Making its own HW, it can be a new beginning for Microsoft, which business is based on licensing
SW to other manufacturers within the "Windows ecosystem" (Reuters, 2012). Global integration of all our major enterprise functions, from service delivery to marketing - has enabled $I B M$ to increase its enterprise productivity savings in more than $\$ 5$ bil. over the past 4 years while improving quality. A globally integrated model allows IBM to focus its capacities on client-oriented work and high growth markets. Among the key profitable factors of Qualcomm belong: higher performance, level of integration, quality, compliance with industry standards, price, time-to market, system cost, design and engineering capabilities, etc. (Qualcomm, 2011). Qualcomm attributes its business success to the increased popularity of smartphones, higher adoption of $3 G$ technologies and the patent portfolio that drives business revenues and profits (Telecoms, 2011). In order to increase its profit, Dell as the top integrated technology solutions provider, will more focus on shifting its portfolio to higher-margin and recurring revenues over time, improving its core business, and maintaining a balance of liquidity, profitability, and growth. The company will support the strategy of supplying everything from HW to SW for corporate customers. Dell has recently tried to expand beyond a consumer arena dominated by mobile devices such as iPad. The shares of the company derive more than $30 \%$ of its revenues from corporate solutions, services and SW (Dell, 2012).

In 2011, the largest expenditures on research and development (R\&D) had Microsoft, Intel and IBM. Microsoft Research (MR) is one of the world's largest IT research organizations. MR closely collaborates with the best universities and research centres to advance the state-of-the-art in IT. The Microsoft R\&D investment in the last years represented $13 \%, 14 \%$, and $15 \%$ of revenues each year. Microsoft invests in R\&D across a wide spectrum of technologies, tools, and platforms including communication and collaboration; information access and organization; entertainment; business and

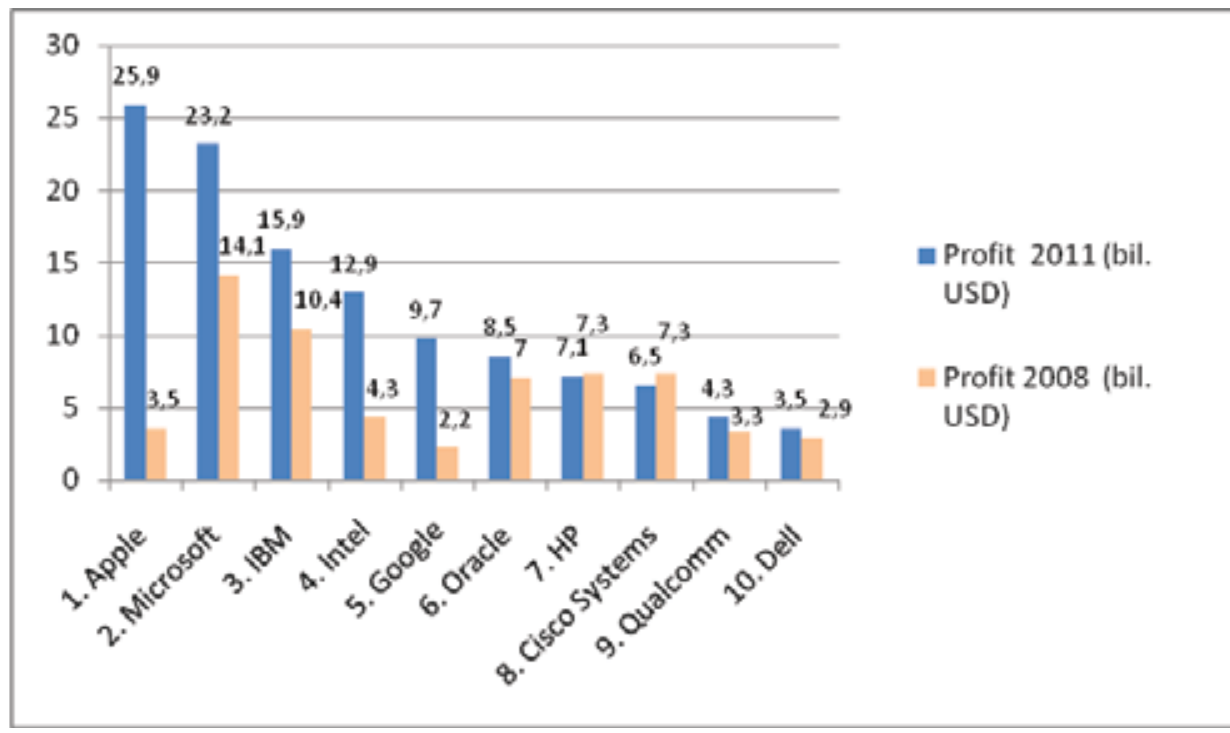

Figure 3: Most successful technology/ICT companies according to profits, Source: (Fortune, 2009a and 2012; JRC, 2009 and 2011) 
e-commerce; advertising; and devices (Microsoft, 2011). Intel invests in world-class design and manufacture of integrated circuits. The company develops technology innovation, such as three-dimensional Tri-Gate and Hi-k metal gate transistor technology. As part of its R\&D, the company plans to introduce a new microarchitecture for notebooks, Ultrabook systems, desktops, and Intel Xeon processors, i.e. approximately every two years. The company refers to this cycle as "tick-tock" technology development cadence. The Intel's R\&D model is also based on the global organization with a teamwork approach to identifying and developing new technologies, leading standards initiatives, and influencing regulatory policies. But, the company centralizes its core cross-business group product initiatives to align and prioritize its $R \& D$ activities across the world (Intel, 2011). IBM equally invests approximately $\$ 6$ billion in $R \& D$ every year, focusing on high-growth, high-value opportunities. The intellectual property rights (IPR) income of about $\$ 1$ billion per year enables the company to investment in R\&D. IBM Research, the global network of researchers works with clients and IBM business units on near-term and mid-term innovations and solutions in the areas from mathematical and material sciences, through chemistry, services, to key computer science. The company has pioneering contributions in artificial intelligence, highspeed processor design, computer architecture, natural language processing, or programming languages. In 2011, the company was awarded the patent leader for the 19 . consecutive year with 6180 patents in 2011 (IBM, 2011). In 2011, the lowest expenditures on R\&D in this group had Dell and Apple. The highest share of R\&D expenditures in the profit had Cisco: 89\%, Qualcomm: 70\%, and Intel: $65 \%$ in 2011. In 2008, it was at Cisco: 48\%, at Qualcomm: $67 \%$, and at Intel similarly: $65 \%$. The highest growth of this share reported Cisco. For example, Apple invested only $9 \%$ of its profits into R\&D in 2011, while in 2008, it was $31 \%$ (Figure 4).
The Apple's ability to compete depends highly upon its ability to secure a continual and timely flow of its products, services and technologies to the market. The company continues to expand the range of its product offerings through $R \& D$, IP licensing and acquisitions of third-party businesses and technology. The company holds IPR to patents and copyrights relating to its iPhone, iPad, Mac and iPod devices, peripherals, SW and services (Apple, 2011). Google invested about $54 \%$ of its profits in R\&D in 2011, while in 2008, it was $32 \%$. The Google R\&D philosophy is to launch innovative products early and often, and then to invest highly in order to make those products better. The company often discloses early stage products at test locations online or directly on Google.com (Google, 2011). Then, it uses user feedback to decide if and how to invest further in those products. Google proprietary technology is not dependent on any single patent or copyright or groups of related patents or copyrights compared to other technology companies.

\subsection{Trends in TM in most successful technology/ICT companies}

New emerging technologies are oriented to overcome existing technology limits, to increase technology performance or to reduce the resources consumption (Westkämper, 2007). The complexity, flexibility and adaptability of new technologies are pushing us to change thinking about how companies do business, how customers are served, how we conduct our work, or how we have fun. The edges between corporate and consumer technology are blurring. Therefore, it is the time to focus on technology as a key driver for growth of our society. In the business, companies must be prepared to recognize and take advantage of new opportunities and risks coming from the new technology trends like context-based services, converging

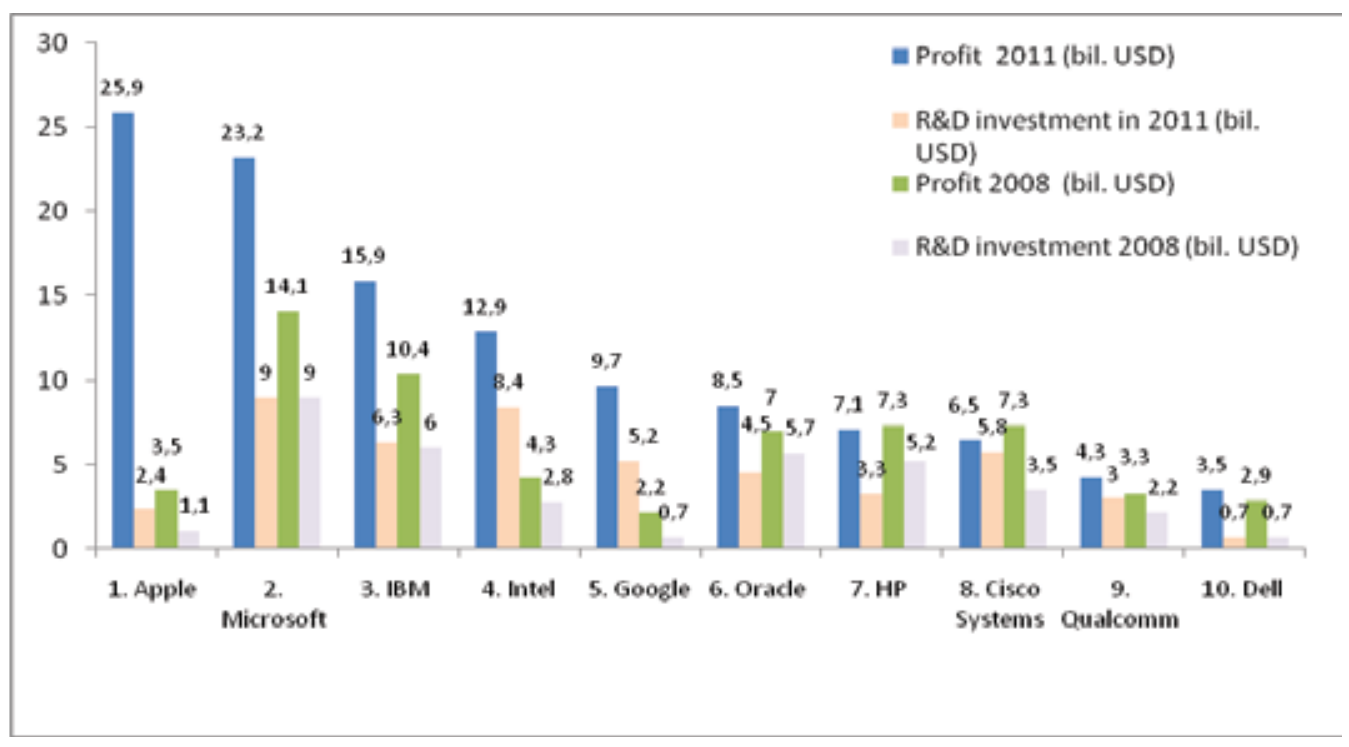

Figure 4: Most successful technology/ICT companies according to profits and R\&D investment, Source: (Fortune, 2009a and 2012; JRC, 2009 and 2011) 
data architectures or social technologies. Driven by technology trends, TM must be performed more systematically and effectively, in terms to increase impacts of new technology trends on customer satisfaction, business growth, cost structure, eco friendliness, etc. TM requires systemic participative planning and design so that every technology project can take a company a step forward. Among the 5 key trends in TM of the best technology/ICT companies belong:

A. Value-added of technological processes mainly depends on systematic and systemic approach to TM, a clear technology vision and strategy, good internal and external relations, on corporate culture that accepts changes and creativity of employees, as well as on flexibility of technological solutions (Boomer, 2006). A business vision should have a clear specification of technology roles in achieving strategic business objectives (Zamora, 2010). Successful technology companies have clearly defined their core technologies in technology strategies or visions. For example, the IBM vision and strategy have enabled the company to stabilize its results in core business areas, while expanding business offerings and targeted markets. The IBM vision is called „Smarter Planet" that presupposes a technology-enabled world that is more instrumented, connected, and intelligent than ever before. The key principles of the IBM strategy are: to deliver value to enterprise clients through integrated business and technology innovation; to shift the business mix to higher-value areas; and to become the premier globally integrated enterprise. These priorities reflect a broad shift in customers' requirements towards integrated solutions, while companies seek higher levels of business values from their IT investment. The IBM priority is to accelerate business progress by equipping its clients with the integrated capabilities such as business analytics, business process management, social business and cloud computing (IBM, 2011). To assist SMEs, many corporations establish so-called 'value-added sellers' to deliver their customers tailor-made solutions. For instance, the Apple Value Added Resellers help companies to simplify and enhance their technology processes leading to improved business processes and economic results. Working with the VA Resellers, a company can obtain customized integrated technology solutions, professional experience, proficiency in the Apple and complementary IT products, and additional services, such as: technology planning, system design, or training (Apple, 2011). Many companies are increasingly employing external technologies within their technology portfolios (Stock and Tatikonda, 2008). TM should keep track of planned core technology paths with expected changes and their impacts on the whole technology system. This means to systematically analyse own technology processes, but also to follow trends/risks outside a company that can have an impact on the competitive advantage (Zamora, 2010). The useful tools in this context are systematic Technology/innovation radar, Technology assessment and subsequent Foresight.

B. TM creates preconditions for proper applications, implementation and realization of strategic objectives of an enterprise through the technological system and constantly monitors technological processes, as if it was the main strategic business asset. For example, before a company begins a technology implementation project for Intel ${ }^{\circledR} A M T$ (Active management of technology), it must have a clear understanding of technology capabilities, how they can be utilized within its environment, and it must review the scope of organizational impacts that the implementation will have. Having identified opportunity areas, this will provide the basis for the technology implementation project and allow embracing the framework for creating technology teams, developing roadmaps for technology improvements, creating infrastructure, project schedules, and deploying the new technology (Intel, 2007). Technology intelligence is a capability of TM that allows companies to determine the technological opportunities and threats with effects on their future growth and survival. It enables to capture and broaden technological information necessary for strategic planning and decision making (Lee et al., 2011). For another example, Oracle Business Intelligence is a complex set of analytical SW products that provide customers with information they need to make better business decisions. These products include: Oracle BI Suite Enterprise Edition, a complex query and analysis server; Oracle Essbase, an online analytical processing server; Oracle BI Publisher, a selfservice production and operational reporting device; and Oracle Real-Time Decisions, a real-time data classification and optimization tool. Customers can access these products from various user interfaces including browserbased interactive dashboards; ad hoc query and analysis; proactive detection and alerts integrated with e-mail; Microsoft Office integration including support for Excel, Word, and PowerPoint; and mobile analytics (Oracle, 2011). New technology thus enables TM to create new technology intelligence capabilities that enable to better achieve strategic business objectives through the technology.

C. The main document that characterizes TM and its relevance to strategic business objectives should be a well communicated technology strategy, preferably formulated as a result of Technology foresight or open technology planning. Many companies look for partners to help them and their stakeholders to work up and implement more complex technology strategies. For example, HP works with thousands of clients (within its Strategic IT Advisory Services) to establish a technology strategy that would adequately detail technology requirements. HP also develops technology strategies and transformation plans as services to their clients. The company widely maps relevant data associated with various technology processes and assigns a value to it that justifies introducing new technology and changing existing technology strategies. Clients can engage with HP to plan and implement new technology and realize technology synergetic plans (ALTO, 2011). A main element of the IBM technology strategy is to focus on becoming the best globally integrated enterprise. The company has implemented a 
complex set of processes and standards worldwide to reduce technology costs and improve collaboration. Since 2005, this global integration has enabled IBM to deliver over $\$ 6$ bil. in productivity and improve service quality, speed and risk management. With about 3500 strategy professionals, the IBM business strategy and change practice prioritize IBM Global Business Services, one of the worlds leading management consulting group. IBM has technology expertise across more than 12 industries: from communications, distribution, financial services, to industrial and public sectors. The IBM technology services offer: establishing an overall technology strategy, helping to establish/evaluate a business architecture or SOA (service-oriented architecture), and helping to improve IT processes to reduce technology cost in a company (IBM, 2011). For another example, the Apple technology strategy prioritizes design and development of own operating systems, HW, application SW, and services to provide customers with new products and solutions including superior ease-of-use, seamless integration, and innovative design. Apple offers customers superior innovation and integration of complex solutions such as the HW (iPhone, iPad, Mac, and iPod), SW (iTunes), and distribution of digital content and applications (iTunes Store, App Store, iBookstore and Mac App Store) (Apple, 2011). Technology strategy should form the bases for measuring efficiency and effectiveness of TM, and for alignment of operational plans and programs even in SMEs.

D. Technological innovation is often a long term incremental process that requires longer-term sources of investment. At the same time, its returns are often longer and more risky than product innovation. Excellence in timely selection and exploitation of technologies that bring the highest benefits is the key process of TM (Farrukh et al., 2004). Therefore, technology innovation processes often require an effective investment strategy and cooperation. Among capital investment possibilities are to buy shares in R\&D companies, acquisitions, mergers, or joint ventures (Spath et al., 2009). As the example, the Qualcomm Ventures (QCV, formed in 2000) with the \$500 mil. fund commitment to make strategic investment in an early-stage of high-technology ventures. QCV has funded numerous companies in the wireless sector, and set up several exclusive regional funds to spur development in key strategic markets, including the $\$ 100$ mil. fund in China and the \$100 mil. fund in Europe (QCV, 2011). Strategic technology partnerships and acquisitions have always played the important role also in the Microsoft innovation financing. In 2010, Microsoft finished up the integration of Yahoo! search with Bing, and these companies together powered more than $25 \%$ of all U.S. searches. In 2011, Microsoft created the well-known joint venture with Nokia aimed at building a new mobile ecosystem. Within this partnership, Nokia will primarily sell Windows-based phones. Despite the problems of Nokia, both companies work together on mobile technology development and marketing that should bring these new joint products to wider market segments and geographies across a broader range of price points (Microsoft, 2011). With 100 million users active on Google+ and over 120 Google integrations to date (including Google Search, YouTube and Android), the Google inter-companies integrations create an important element of its technology strategy and capital investment (Google, 2011). An important element of the Oracle's technology strategy and product innovation efforts is to develop technology solutions in collaboration to obtain higher efficiencies and provide increased IT performance, reliability, and security to customers. These pre-integrated and optimized combinations of SW and HW products are called 'engineered systems'. Two of the important engineered systems are Oracle Exadata Database Machine and Oracle Exalogic Elastic Cloud. These have high performance, scalability and ability to be shared by multiple applications; they are well suited for IT consolidation and cloud computing (Oracle, 2011). Despite the fact that these external technology integrations dominate in the technology industry, TM has to consider also their side effects such as: operating difficulties, dilution, and other dangerous consequences that may adversely impact on business results.

E. An important factor in success and efficiency of TM operations is an Open technology strategy, which implies creation of a functional network with other businesses, not only from the technology sector, but also with $\mathrm{R} \& \mathrm{D}$, education, finance, or marketing companies. The Cisco technology strategy offers an open interoperable technology architecture that enables its customers to collaborate on the Cisco product development regardless of a device, content, location, or an interaction style. In 2011, Cisco presented several new collaborative solutions including: Cisco Quad, an enterprise social software platform; Cisco Social Miner, a social media solution for proactive customer care; Cisco Jabber, an enterprise application for presence, instant messaging, web conferencing, desktop sharing, voice and video on mobile devices, laptops and applications; Cisco WebEx for web-based collaboration with presentations, applications, documents, integrated audio and high quality video on tablets and desktops; and new desktop virtualization endpoints for thin client collaboration applications (Cisco, 2011). For another example, Oracle Application Integration Architecture provides an open framework for creating adaptable, crossapplication business processes. These software products are sold as integrated sets or on a component principle, and all are built on open architectures that are designed for flexible configuration and open, multi-vendor integration. Oracle is an open standards leader. Its technology solutions are based on open industry standards so that the products could simplify customers' interoperability and security, and decrease costs of deployment. Within this open technology strategy, Oracle cooperates with about 100 standards-setting organizations, 300 technology managers, 600 technical working groups, and about 90 policy committees (Oracle, 2011). Despite the already mentioned disadvantages, this approach helps companies avoid vendor lock-in, enables an open access to technical 
details and interfaces, lowers barriers to innovation, and reduces cost of technology investment.

Among the 5 key trends in technology innovation of the best technology/ICT companies belong:

A. Currently, significant support for TM can be provided by complex ICT solutions and 'clouds'. Social robots, intelligent software applications, and staff who can work remotely, all using ICT. The trends will be in the future of communication technology and advanced data sharing - from desktop and mobile applications through the cloud to telepresence. A majority of business information of companies is being situated outside their corporate databases; therefore, an unstructured content analysis and a text analysis have become imperative. Content management, technology classification and categorization are one of the most important processes in TM, because these help managers to manage important information about a technology. A knowledge management portal within TM should include tools to organize content, elements, processes, inputs, outputs, business intelligence, knowledges and capacities related to the use of a technology in a company. Thus, this portal impacts all the managerial levels in the company (Nieto et al., 2010). In the next decade, a profession of application developers will record the largest increase of all IT professions. These are particular jobs of mobile applications developers, whose numbers will increase by almost a third to 2020. According to the U.S. Bureau of Labor Statistics, there were more than 500-thousand of SW developers in the U.S. in 2008, and in six years, this should be in 175-thousand more (BLS. GOW, 2012). The increase in demand may be expected also in other professions such as network and security specialists, computer game designers or web developers. The mobile platform will have become the main communications and interaction platform by early adopting best-practice organizations and by SMEs. The capabilities afforded users of smartphones and tablet devices grow rapidly. Tablets will become virtual classrooms, and an emerging class of tools will enable companies manage almost all aspects of their business digitally. For example, the digital factory modeling in a standardised 3D system display has become a trend in many production businesses (Westkämper, 2007). Microsoft offers Windows Small Business Server for SMEs as an affordable server solution providing networking, security, databasing, line-of-business support, and remote access, etc. This server enables to optimize technology processes and costs by using an intuitive management interface, one that presents relevant system information and matching set of tasks (Microsoft, 2012a). Cloud computing has become a popular way to increase own IT capacities without investing in new HW, training people, or licensing new SW. Cloud computing means a subscription-based or pay-per-use service on the Internet. As the example, Oracle Cloud Services offer complex SW and HW management and maintenance for customers hosted at Oracle data center facilities, select partner data centers or physically on-site at customer facilities. Advanced Customer Services provides support, both onsite and remote, to Oracle customers (Oracle, 2011). IBM SmartCloud ${ }^{\mathrm{TM}}$ Entry is a cloud SW offering a web-based interface. A company can monitor and manage this environment for improved efficiency and utilization of their data (IBM, 2012a). Cloud services enable TM to simplify storage of big data; to cut off time to value for new workloads from months to a few days; to simplify administration with an intuitive interface for managing projects, users, workloads, resources, billing, or metering.

B. Another trend, which can be used to draw the future of MT, is the flood of data that are available to firms. How can TM manage the so-called 'big data'? According to IBM, every day about 15 petabytes of data is created, which is 8 times more than can be found in all libraries in the USA (Gartner, 2011). Big data are data sets so large and complex that they become difficult to work with using on-hand database management tools. These difficulties include searching, capture, storage, sharing, analysis, or visualization. The trend to large data sets management includes searching for the additional information derivable from analyses of a smaller data set of related data, and then allowing correlations to be found, linking citations, combat piracy, etc. There is also a growing demand for people who will be able to manage the onset of both structured and unstructured data, such as photos, videos or audio recordings. Appropriate converging data architectures to structured forms of data enable TM to appropriately control them. But, as information becomes the most valuable asset for many companies, data architectures require a change and link between traditional and new databases and systems to keep the business value. New approaches to managing data provide a completely new concept of data control - the ability to turn data into new values and 'bridge technology' that will enable companies to mix old and new database forms are expected (Accenture, 2012a). For example, the Oracle SW products enable integration within public and private clouds, including identity and access management, Service-oriented architecture and process integration, and data integration and master data management. The Oracle Fusion Middleware SW includes the following functions: application server and application grid; and business process management; SOA; business intelligence; identity and access management; data integration; content management; portals and user interaction; and development tools (Oracle, 2011). TM is thus forced to seek resources and tools for large data management and to initiate new data architectures development to more effectively processing both structured and unstructured data.

C. Industrialized data services: Many technology companies indicate the tendency that their data bring a higher value when they are sharing and different stakeholders are involved in that broader data sharing. Companies can broader share their data because there have been a dramatic improvement in the technology and capabilities used to manage, process, and store data. Many of these processes have been incubated by the technology-based 
companies, such as Amazon, Facebook, Google, Yahoo, or Netflix. Microsoft SkyDrive, Apple iCloud, Evernote, and Box are all intended to store and share customers' content. For example, with Google Drive tool, customers can store documents, photos, music, videos, etc., all in one place. This enables to syncs with a mobile device or PC. When a customer makes a change from one device, it will automatically show up in other devices (Google, 2012). A data sharing approach can accelerate companies toward the trend of standardized and industrialized data management. The emergence of standardized data platforms may enable TM to share its data as a new business. These data services are based on an as-needed approach as new use cases appear (Accenture, 2012b). The main question here is who will be responsible for the data at each stage of their life cycle? At the beginning, it can be $\mathrm{TM}$, then specialised Data management, but the next step would involve 'open data exchanges', i.e. sharing data with external partners such as suppliers and customers. This requires the establishment of special capacities for open data management. In the future, the best technology companies will be necessary to strike the balance between constraints and availabilities for their data, based on well defined data management strategies.

D. Orchestrated Analytical Security (OAS): Companies are more and more connected also through other non-traditional forms: intranets, radio RFID tags, GPS devices, bar code readers, etc. These data links can increase business risks, therefore companies are forces to improve data security management. In efforts to more flexibly understand and anticipate needs of customers, companies analyze and process data in real-time (Hempfield, 2011). Real-time analytics may require developing 'datacentric mentality', leveraging new data platform concepts to design, to implement, and to run systems that continually improve levels of business protection. By taking a datacentric view toward security and running the equivalent of analytics-driven security, these can help companies struggle with data risks. OAS can help prioritize the risks of IT security breaches; especially, specify data, systems, and initiatives that are most important for the business (Accenture, 2012b). As the example, Cisco security solutions span network and content security systems that are designed to enable highly secure collaboration. The products in this category include firewall, intrusion prevention, remote access, virtual private networks, unified client, web and email security and network security (Cisco, 2011). For TM, it means more intensive collaboration with IT security teams; aligning their strategies and goals and ensuring that data security will not be a barrier to technology and business priorities.

E. Social-driven technologies have become a strong catalyst that is changing the ways companies use social applications to interact with the environment. For example, Facebook to a large extent substitutes e-mails and text messages as a primary tool for communicating with family, friends, etc. Social media has become important for companies as well, although many times as an additional marketing or PR tool. Online forums and Twitter feeds are important sources of business feedback for marketers, TM or product developers to recognize what consumers really want. Many companies use social platforms and social design mechanics to better organize their interactions with stakeholders. Business call center applications, web presence, customer relationship management, or other consumer channels are integrated and 'socialenabled'. Companies need to search for new trends and opportunities via social media, such as social polling - WayIn or Yahoo's IntoNow (Accenture, 2012a). But social-driven technologies also move beyond social communication, towards analysing social intelligence. This activity is realized by studying and modeling social behavior, by capturing human social dynamics, by creating artificial social agents, by generating and managing actionable social knowledge (Fei-Yue et al., 2007). For example, The Microsoft Machine Learning and Applied Statistics (MLAS) group is focused on building methods and means to learn from data, by creating SW with social-oriented applications. Among the current applications belong: Online advertising/eCommerce; Recommendation systems/collaborative filtering - means for predicting customers' preferences based on the information about user preferences or demographics; Computational biology - machine learning technology that analyses biological data. Etc (Microsoft, 2012b). These processes can be a very important source of information in TM within technology identification processes, for better Technology assessment or Foresight.

\section{Conclusions}

The development of TM can be characterized as a gradual process of dissemination, updating, and an integrated use of new technology and related know-how. Today, Technology management education has more 25 years. And, almost all main universities provide educational programs in TM, technology strategy/planning/Foresight, technology-based entrepreneurship, technology innovation, technology transfer, etc. (Yanez et al., 2010). Modern TM requires effective identification, selection, acquisition, research, use and protection of technologies (elements, processes and infrastructure) necessary to achieve and sustain market positions and business performance in conformity with strategic objectives. Companies must be prepared to recognize and to take advantage of new opportunities and risks coming from the new technology management trends like: open technology strategy, 'clouds', industrialized data services or social technologies, which can bring new more efficient ways of business management. Driven by these trends, TM must be performed more systematically and effectively, in terms to increase impacts of new technology trends on customer satisfaction, business growth, cost structure, eco friendliness, etc.

Among the most successful technological/ICT companies belong: Apple, Microsoft, IBM, Intel, Google, Oracle, etc. If we look at the financial results of these companies according 
to revenues in 2011, then the highest revenues had HP, Apple and IBM, while, Qualcomm and Oracle had the smallest revenues in 2011. The best technological enterprises in terms of their profits are Apple, Microsoft and IBM. The lowest profits reported within this rank Qualcomm and Dell. In the Global 500 rank, among the top technology companies dominates HP, followed by IBM. In this rank of the best global corporations, HP and Apple reported substantial growth compared to 2008. In 2011, the largest expenditures on R\&D had Microsoft, Intel and IBM. While, the highest growth $(+200 \%)$ of these expenditures reported Intel compared to 2008. And, HP reported the largest decline $(-37 \%)$ in its $\mathrm{R} \& \mathrm{D}$ investment compared to 2008. The reason may be in the shift of investment to better protect organization against a wide range of security attacks. HP has established a global network of security analysts who look for vulnerabilities that were not publicly disclosed, in an effort to proactively reduce business risks.

In summary, there are two key differences between developed and developing countries related to the TM agenda due to the different intensity of a national R\&D support system. Developed economies mainly support enforcing innovation performance, while developing countries more support managing existing technologies (Cetindamar et al., 2009). This has an impact on trends in MT in different countries and industries. In the last two decades, the expansion of intelligent ICT in many sectors has caused higher and higher requirements for TM. Classification, simulation and modeling of technological processes from development of a technological concept, zero series, and beta-testing to commercial production increasingly reduce innovation time, but also production and operating cost. Traditional in-door TM is being completed by cooperative TM within open-innovation networks, or Living Labs. The most common trend in any sector is integrated TM within different range of participants and capacities, and taking advantage of higher openness of technology strategies, these have become the important factors of business success.

\section{Literature:}

Accenture (2010). Accenture Technology Vision 2010: Everything Elastic, Accenture. Available at http://www.accenture.com/ us-en/pages/insight-future-information-technology.aspx, May 2012.

Accenture (2011): Accenture Technology Vision 2011: The Technology Waves that are Reshaping the Business Landscape, Accenture. Available at http://www.accenture.com/us-en/technology/technology-labs/Pages/insight-accenture-technologyvision-2011.aspx , June 2012.

Accenture (2012a). Accenture Technology Vision 2012: Emerging Technology Trends for IT Leaders, Accenture. Available at http://www.accenture.com/us-en/technology/technology-labs/ Pages/insight-accenture-technology-vision-2012.aspx, July 2012.

Accenture, (2012b). Context-based Services, Accenture. Available at http://www.accenture.com/SiteCollectionDocuments/PDF/contextbasedservices.pdf, July 2012.

Alto, P. (2011). HP Technology Consulting Services Help Clients Align its Strategy with Business Goals, HP. Available at http:// www.hp.com/hpinfo/newsroom/press/2011/110425xa.html, April 2011.
Apple (2011). Annual report 2011, Apple. Available at: http:// investor.apple.com/secfiling.cfm?filingID=1193125-11282113\&CIK=320193, January 2013.

Arch-int, S. \& Batanov, D. N. (2003). Development of industrial information systems on the web using business components. Computers in Industry, 50(2), 231-250, http://dx.doi. org/10.1016/S0166-3615(02)00122-7

BLS.GOW (2012). Occupational Employment Statistics, Bureau of Labor Statistics. Avalable at http://www.bls.gov/oes/current/ oes151132.htm, June 2012.

Bohr, M.T. (1996). Technology development strategies for the $21^{\text {st }}$ century. Applied Surface Science, 100/101, 534-540, http:// dx.doi.org/10.1016/0169-4332(96)00335-2

Boomer, L.G. (2006). The 10 rules of technology management. Accounting Today, February, 20-23, ISSN: 1044-5714.

Brem, A. \& Voigt, K. (2009). Integration of market pull and technology push in the corporate front end and innovation management-Insights from the German software industry. Technovation. 29(5), 351-367, http://dx.doi.org/10.1016/j.technovation.2008.06.003

Cetindamar, D., Wasti, S.N., Ansal, H. \& Beyhan, B. (2009). Does technology management research diverges or converges in developing and developed countries?. Technovation, 29, 45-58, http://dx.doi.org/10.1016\%2Fj.technovation.2008.04.002

CISCO (2011). Annual report 2011, Cisco. Available at http://www. cisco.com/assets/cdc_content_elements/docs/annualreports/ media/2011-ar.pdf, January 2013.

DELL (2011). Annual report 2011, Dell. Available at http://i.dell. com/sites/content/corporate/secure/en/Documents/FY11_YIR_ Letter_with10K.pdf, June 2012.

DELL (2012). Dell to dole out more cash, corporate push quickens, Reuters. Available from http://www.reuters.com/article/2012/06/12/us-dell-dividend-idUSBRE85B1FA20120612, July 2012.

Drejer, A. (1997). The discipline of management of technology, based on considerations related to technology. Technovation, 17(5), 253-265, http://dx.doi.org/10.1016/S0166-4972(96)00107-1

Farrukh, C., Fraser, P., Hadjidakis, D., Phaal, R., Probert, D. \& Tainsh, D. (2004). Developing an integrated technology management process. Research Technology Management, 47(4), 39-46.

Fei-Yue, W., Carley, K.M., Zeng, D. \& Mao, W. (2007). Social Computing: From Social Informatics to Social Intelligence. Intelligent Systems, IEEE, 22(2), 79-83, http://dx.doi. org/10.1109/MIS.2007.41

FORTUNE (2009a). 20 most profitable tech companies, Magazine Fortune. Available at http://money.cnn.com/galleries/2008/fortune/0804/gallery.tech_profits.fortune/12.html, March 2010.

FORTUNE (2009b). Fortune 500, Magazine Fortune. available at http://money.cnn.com/magazines/fortune/fortune500/2008/ full_list/401_500.html, March 2010.

FORTUNE (2012). Global 500, Magazine Fortune. Available at http://money.cnn.com/magazines/fortune/global500/2011/ index.html, June 2012.

Google (2011). Annual report 2011, Google. Available at http:// investor.google.com/proxy.html, June 2012.

Google (2012). Google drive, Google, Available at https://drive. google.com/start?continue=http://drive.google.com/\%23\#home, January 2013.

Guice, J. (1999). Designing the future: the culture of new trends in science and technology. Research Policy, 28, 81-98, http:// dx.doi.org/10.1016/S0048-7333(98)00105-X

Hempfield, C.W. (2011). Data Quality? That's IT's problem not mine, Pitney Bowes Business Insight. Available at www.personallypb.com/pdf/data-quality/, July 2012. 
Hodgson, P.D. \& Cardew-Hall, M.J. (1998). Process and product integration: research challenges. Journal of Materials Processing Technology, 80-81, 1-7, http://dx.doi.org/10.1016/ S0924-0136(98)00204-0

HP (2011). Annual report 2011, HP. Available at http://h30261. www3.hp.com/phoenix.zhtml?c=71087\&p=irol-reportsannual, June 2012

IBM (2011). Annual report 2011, IBM. Available at http://www.ibm. com/annualreport/2011/bin/assets/2011_ibm_annual.pdf, June 2012.

IBM (2012a). IBM SmartCloud Entry, IBM. Available at http:// www-03.ibm.com/systems/x/solutions/cloud/starterkit/index. html, July 2012.

IBM (2012b). Improving operational decision making for competitive advantage, $I B M$. Available at http://www-01.ibm.com/software/de/beweglich-bleiben/pdf/BPM/Improving-operationaldecisionmaking-for-competitive-advantage.pdf, July 2012

INTEL (2011). Annual report 2011, Intel. Available at http:// www.intc.com/intelAR2011/common/pdfs/Intel_2011_Annual_ Report_and_Form_10-K.pdf, June 2012.

Jemala, L. (2010). Innovation of Leadership and Management. Forum Statisticum Slovacum, VII(4), 45-51, ISSN: 1336-7420.

Jemala, M. (2010). Evolution of Foresight in the Global Historical Context. Foresight, 12, (4), 65-81, ISSN: 1463-6689.

Jemala, M. (2012). Nature of Foresight Planning. LAP LAMBERT Academic Publishing: Saarbrücken, ISBN: 978-3659131509.

JRC (2009). The 2009 EU Industrial R\&D Investment Scoreboard. European Commission, Joint Research Centre, Institute for Prospective Technological Studies Edificio Expo, November, ISBN: 978-92-79-14058-7.

JRC (2011). The 2011 EU Industrial R\&D Investment Scoreboard. European Commission, Joint Research Centre, Institute for Prospective Technological Studies Edificio Expo, November, ISBN: 978-92-79-21604-6.

Kaplinski, O. (2009). Problems of the information technologies use in Polish construction sector: State of the art. Achives of Civil Engineering, 55(2), 173-197, ISSN: 1230-2945.

Kepczyk, R. H. (2004). Technology-Resources. Strategic Technology Management. Tax Practice Management, May-June, 11-12, ISSN: 1541-9169.

Kim, J., Suh, W. \& Lee, H. (2003). Hypermedia modeling for linking knowledge to data warehousing system. Expert Systems with Applications, 24, 103-114, http://dx.doi.org/10.1016/S09574174(02)00088-X

Larson, Ch. F. (2007). 50 years of change in industrial research and technology management. Research and technology management, January-February, 26-31, ISSN: 0895-6308.

Lee, S., Mortara, L., Kerr, C., Phaal, R. \& Probert, D. (2011) Corporate document mining for technology intelligence: An analysis of needs, utilisation and possibilities. International Journal of Technology Intelligence and Planning. 7(2), 110-127, http://dx.doi.org/10.1504/IJTIP.2011.043197

Leifer, R., McDdermott, Ch.M., O'Connor, G.C. \& Peters, L.S. (2000). Radical Innovation: How Mature Companies Can Outsmart Upstarts. Boston: Harvard Business School Press, ISBN: 978-0875-849-034.

Liao, S. (2005): Technology management methodologies and applications: A literature review from 1995 to 2003. Technovation, 24(4), 381-393, http://dx.doi.org/10.1016/j.technovation.2003.08.002

Microsoft (2011). Annual report 2011, Microsoft. Available at http:// www.microsoft.com/investor/reports/ar11/download_center. html, June 2012
Microsoft (2012a). Cloud Computing, Microsoft. Available at http:// www.microsoft.com/enterprise/viewpoints/cloud-services/ default.aspx\#fbid=lxWjNXhGTrf, July 2012.

Microsoft (2012b). Machine Learning and Applied Statistics, Microsoft research. Available at http://research.microsoft.com/ en-us/groups/mlas/, July 2012.

Nieto, B.W., Luna, A.C. \& Ramos, R.J. (2010). A Model of Technological Platform for the Knowledge Management Organization. World Academy of Science, Engineering and Technology, 63, 399-403, ISSN: 2010-376X.

Oracle (2011). Annual report 2011, Oracle. Available at http://www.oracle.com/us/corporate/investor-relations/ financials/10k-2011-423237.pdf, June 2012.

Pelc, K. I. (2002). Knowledge Mapping. The Consolidation of the Technology Management Discipline. Knowledge, Technology and Policy, 15(3), 36-44, http://dx.doi.org/10.1007/s12130-0021003-3

Poole, S. \& Simon, M. (1997). Technological trends, product design and the environment. Design Studies, 18(3), 237-248, ISSN: 0142-694X.

QUALCOMM (2011). Annual report 2011, Qualcomm. Available at http://files.shareholder.com/downloads/QCOM/1924045956 x0x523322/6ebeb924-8e0d-4829-b233-2ed3d7fd3625/2011 Annual_Report_on_Form_10-K.pdf, June 2012.

Reddy, P. (1997). New trends in globalization of corporate R\&D and implications for innovation capability in host countries: a survey from India. World Development, 25(11), 1821-1837, http:// dx.doi.org/10.1016/S0305-750X(97)00079-X

Reuters (2012). Talk of Microsoft tablet resurfaces, Microsoft. Available at, http://www.reuters.com/article/2012/06/15/usmicrosoft-windows-tablet-idUSBRE85E1K020120615, June 2012.

Roberts, Ch.B. (1996). The Impact of IT on the Management of System Design. Technology in Society, 18(3), 333-355, ISSN: 0160-791X.

Rubenstein, A. H. (1994). Trends in Technology Management Revisited. IEEE Transactions on Engineering Management, 41(4), 335-341, http://dx.doi.org/10.1109/17.364555

Sahlman, K. (2010). Elements of strategic technology management, University of Oulu. Available at http://herkules.oulu.fi/ isbn9789514262500/isbn9789514262500.pdf , June 2012.

Sahlman, K. \& Haapasalo, H. (2009). Perceptions of Strategic Management of Technology in Small High-Tech Enterprises. In PICMET 2009 Proceedings, August 2-6, 2009, Portland, Oregon, USA.

Saloner, G., Shepard, A. \& Podolny, J. (2001). Strategic management. New York: John Wiley and Sons, ISBN: 978-0-470-00947-5.

Schain, M. A. \& Judt, T. (2001). The Marshall Plan: Fifty Years After (Europe in Transition: The NYU European Studies), New York: Palgrave Macmillan, ISBN: 0312229623.

Solow, R. (1957). Technical change and the aggregate production function. Review of Economics and Statistics, 39, 312-330.

Spath, D., Renz, K.Ch. \& Seidenstricker, S. (2009). Technology management. In Schlick, C.M.: Industrial Engineering and Ergonomics. Berlin: Springer-Verlag, ISBN: 978-3-642-012938.

Stock, G. N. \& Tatikonda, M. V. (2008). The joint influence of technology uncertainty and interorganizational interaction on external technology integration success. Journal of Operations Management, 26, 65-80, http://dx.doi.org/10.1016/j. jom.2007.04.003

Telecoms (2011). Qualcomm posts sharp rise in profit for 2011, Telecoms. Available at http://www.telecoms.com/35943/qualcomm-posts-sharp-rise-in-profit-and-revenue-for-2011/, July 2012. 
Westkämper, E. (2007). Strategic Development of Factories under the Influence of Emergent Technologies. CIRP Annals - Manufacturing Technology, 56(1), 419-422, http://dx.doi. org/10.1016/j.cirp.2007.05.100

Yanez, M., Khalil, T. M. \& Walsh, S. T. (2010). IAMOT and Education: Defining a Technology and Innovation Management (TIM) Body-of-Knowledge (BoK) for graduate education (TIM BoK). Technovation, 30(7-8), 389-400, http://dx.doi. org/10.1016/j.technovation.2010.03.007

Zamora, E. A. (2010). A Management of Technology Framework for MSME Success and Sustainability. Philippine Management Review, 17, 21-51, ISSN: 1656-5363.
Marek Jemala currently teaches and conducts research at the School of Engineering and Management of the University of Nova Gorica. His research interests include topics on technology and innovation management, strategic foresight, open innovation, IP management and related issues. He is an author of 5 books and numerous scientific articles covering these topics. 